\title{
Time effects on the stress-strain behaviour of natural soft clays
}

\author{
J. GRAHAM, J. H. A. CROOKS and A. L. BELL (1983). Géotechnique 33, No. 3, 327-340
}

Dr John H. Schmertmann, Schmertmann and Crapps, Inc. Gainesville, Florida

The Paper has stimulated the writer to comment on the soil structure changes that take place with strain and with time. The writer considers two concepts here

(a) the important differences in time effects when drainage is allowed during strain

(b) the contribution of permanent soil structure change during secondary aging to the increase in the clay preconsolidation yield point, i.e. to the quasi-preconsolidation effect.

The writer considers that the Authors' exclusive use of undrained testing to measure time rate effects in the mobilization of clay shear strength constitutes an important limitation to the conclusions they can extract from their test results.

Figure 4 of the Paper gives seven examples of the linear decrease in undrained strength with the $\log$ of strain rate, with $0.003 \%$ per hour the smallest rate shown. For the purpose of discussion, imagine carrying the Fig. 4 trends for undrained shear to extremely small strain rates. These trends suggest that no clay could reach a stable equilibrium condition (approximately zero strain rate) because its strength would diminish to nearly zero. This contradicts what is known about real clay behaviour, namely that aging usually tends to increase clay strength and helps the clay to attain a stable condition in the field. Why this contradiction? The answer probably involves the drainage that can take place in conjunction with very low strain rates. The writer proposes that how shear strength varies due to different strain rate may depend on the drainage that can take place during the shear strain.

Consider the aforementioned $0.003 \%$ per hour rate in Fig. 4 of the Paper: the writer judges that most clays strained at that rate or less, or 14 or more days for each $1 \%$ compression, would do so under at least significantly partially drained, and perhaps even essentially fully drained conditions. This would almost certainly be the case for laboratory triaxial specimens of ordinary size and with ordinary boundary drainage conditions. By considering strain-rate effects in the direction of low rates of strain, the writer believes that clay strength behaviour in the field may differ greatly from the undrained test results reported by the Authors, not only in magnitude but also in the direction of strain-rate effects. The following is some laboratory test evidence to support this.

Figure 1 shows the comparative results from a series of drained compression tests on machine extruded, duplicate specimens of kaolinite, tested in an identical manner with the same equipment with only strain rate varied (Schmertmann \& Hall, 1962; Schmertmann, 1982). The writer allowed drainage and controlled pore pressures in all these tests such that they strained at the same constant value of major principal effective stress, $\sigma_{1}{ }^{\prime}$. The top part of Fig. 1 shows the deviator stress against strain curves obtained using a constant $\sigma_{1}{ }^{\prime}=3 \cdot 30$, after isotropic normal consolidation to $\sigma_{\mathrm{c}}{ }^{\prime}=$ $3.50 \mathrm{~kg} / \mathrm{cm}^{2}$. It can be seen that the mobilized shear resistance of this drained clay increased with reduced strain rate rather than decreased as suggested by the data from undrained tests in Fig. 7 of the Paper.

The writer does not know if all, or even most, other clays would show similar drained strainrate effects similar to the kaolinite in Fig. 1 because he knows of only this series of drained comparative tests. However, it seems that the field behaviour evidence and the above available laboratory evidence at least suggests that strainrate effects in the ficld may producc an increase in the ability of a clay structure to mobilize its shear resistance rather than the decrease suggested by the Authors' results from undrained testing. The Authors' strength-decrease results would then apply only to the strain-rate range that would keep the clay essentially undrained during the strain. This might perhaps be limited to the condition of a clay straining rapidly after a rapid increase in load places its structure beyond the plastic yield condition while the load continues to act.

The writer also has a possible explanation for why the undrained strength decreases but the drained strength increases with reducing strain 

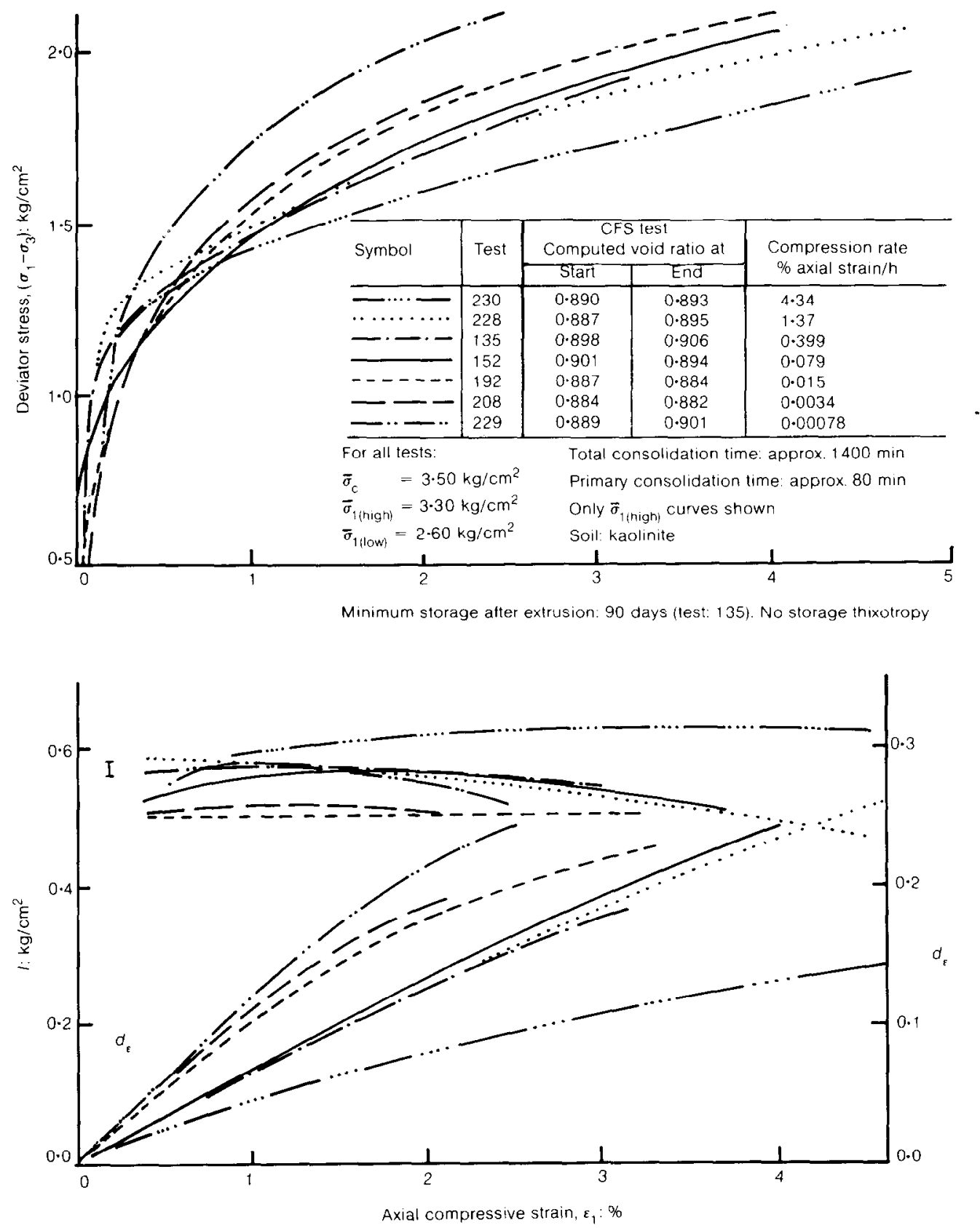

Fig. 1. Effect of rate of compression on the IDS-test results obtained from duplicate specimens of remoulded, saturated kaolinite clay $\left(1 \mathrm{~kg} / \mathrm{cm}^{2}=98 \mathrm{kPa}=102\right.$ ton $\left.\mathrm{f} / \mathrm{ft}^{2}\right)$

rate. Geotechnical engineers well know that the dispersion of a natural clay structure produced by mechanical remoulding usually produces a decrease in undrained clay modulus and strength. They describe the ratio of undisturbed to remoulded undrained strength by a number representing the sensitivity of the clay. They perhaps do not know so well that the same dispersion under drained conditions will usually (when not at the critical state) produce an increase in the ability of the clay structure to mobilize its subsequent shear resistance, with 
the increase most pronounced at low subsequent strains. Schmertmann $(1976,1982)$ presents a more complete discussion of this behaviour.

Mobilized soil shear strength can be separated into two generalized Hvorslev-type components $I$ and $D$. The $D$ component denotes that part of mobilized shear resistance that appears to depend linearly on effective stress, or $D=\sigma^{\prime} d_{\varepsilon} . D$ or $d_{\varepsilon}$ expresses a soil friction behaviour. The references demonstrate that an increasing $D$ component correlates with increasing clay structure dispersion. The bottom part of Fig. 1 shows that the $D$ component (expressed as $d_{\varepsilon}$ ) at any strain increases with decreasing rate of strain, while the $I$ component does not change. Thus, the increasing amount of dispersion that can take place over a given strain interval with reduced strain rate and drained conditions accounts for the increased ability of a clay to mobilize its shear resistance at any strain. The writer believes that all natural clay structures not yet at the critical state tend to disperse partially with time, irrespective of the drainage allowed (although drainage and other factors may affect the degree and rate of this dispersion). Dispersion under undrained conditions will produce a decrease in undrained strength, as by remoulding, while dispersion under drained conditions will produce an increase in strength, as in Fig. 1.

The Authors presented additional evidence in Fig. 8 of the Paper to support the opinion, originally and consistently held by Leonards (1980), that the quasi-preconsolidation effect does not simply result from rate-of-strain effects during secondary aging. They agreed it did not disappear in their tests after a correction for strain rate. The writer wishes to add further support to the Authors' and Leonards' opinion on this matter, which has important practical applications. He will do this by further application of the aforementioned concepts of draincd particle dispersion and strength increase effects.

Allowing significant time for secondary compression aging will also allow significant particle dispersion to take place. But, unlike the undrained test data in Fig. 7, the dispersion during aging in the oedometer test takes place under fully drained conditions. This dispersion will in turn produce a stiffening of the clay structure as a consequence of the increase in its $D$ component with dispersion. This effect of dispersion will increase the yield point strength of the clay structure and thus increase its apparent preconsolidation stress in one-dimensional (or any other) loading under drained conditions.

The writer believes that the quasipreconsolidation effect results primarily from such a non-reversible, dispersive soil structure change and not from some viscous-like soil strain-rate behaviour. He has even detailed a quantitative theory which appears to account for the magnitude of reported quasipreconsolidation increments without the need to include any viscous-like rate effects (Schmertmann, 1982). The writer therefore believes that engineers may consider the quasipreconsolidation effect as reliable for use in foundation design.

\section{REFERENCES}

Schmertmann, J. H. \& Hall, J. R., Jr. (1962). J. Soil Mech. Fdns Div. Am. Soc. Civ. Engrs 88, SM 4, 163-167.

Schmertmann, J. H. (1976). The shear behavior of soil with constant structure. In Laurits Bjerrum Memorial Volume, pp 65-98. Oslo: Norwegian Geotechnical Institute.

Schmertmann, J. H. (1982). A general time-related soil friction increase phenomenon, pp 456-484. American Society for Testing and Materials. Special technical publication 740 .

\section{Dr E. W. Brand, Geotechnical Control Office, Hong Kong}

The Paper makes a significant contribution to the understanding of the effects of rate of strain on the stress-strain-strength characteristics of soft clays. Of particular importance is the conclusion that the shear rate effect on the undrained shear strength lies in the narrow range for all clays of $10-20 \%$ for a tenfold change in strain rate, and that the value of $\rho_{0.1}$ is independent of clay plasticity. The writer has a small amount of additional data for soft Bangkok clay which might narrow the limits of $\rho_{0.1}$ even further.

Soft Bangkok clay is a young marine sediment that covers a total area of about $10000 \mathrm{~km}^{2}$ of the Lower Central Plain of Thailand. It varies in thickness from about $15 \mathrm{~m}$ at the coast of the Gulf of Thailand to $7 \mathrm{~m}$ at Ayuthaya $100 \mathrm{~km}$ north. The water content decreases from about $150 \%$ to $90 \%$ in the same distance, and the vane shear strength at shallow depths increases from less than $10 \mathrm{kPa}$ near the coast to about $30 \mathrm{kPa}$ at Ayuthaya. The Atterberg limits decrease with distance from the sea, the plasticity index also decreasing northwards from about $90 \%$ to less than $55 \%$.

The data quoted in the Paper for shear rate effects on Bangkok clay were published by Bjerrum (1969) at a time when the Norwegian 


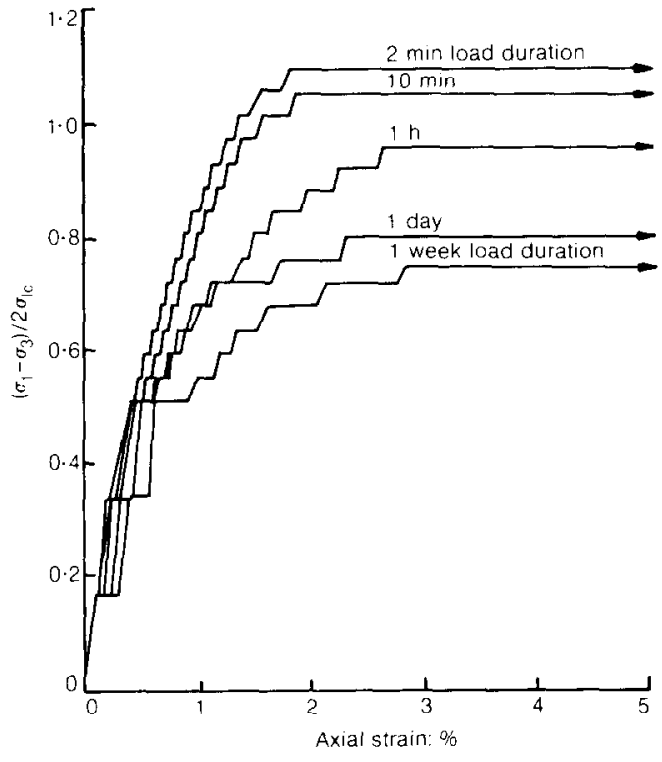

Fig. 2. Stress-strain curves for controlled-stress triaxial tests on Bangpli clay (Sunghitakul, 1976)

Geotechnical Institute was involved with a number of test embankments built to failure $10 \mathrm{~km}$ from the coastline to provide design information for the highway to link Bangkok with the south-eastern coastal town of Siracha. It would seem that Bjerrum presented only preliminary results of the laboratory test programme, because Eide \& Holmberg (1972) and Holmberg (1972) later presented undrained triaxial and simple shear data for clay from the same site, from which they concluded that $\rho_{0.1}$ was in fact only about $10 \%$. The Bangkok clay data points shown in Figs 6 and 7 of the Paper should therefore be adjusted accordingly.

In addition to the Siracha data already referred to, there are two other good sets of data to show the shear rate effects on the undrained shear strength of soft Bangkok clay. Sunghitakul (1976) conducted a series of controlled-stress triaxial tests on samples from a depth of 5.0 $5.5 \mathrm{~m}$ at Bangpli (Brand, Moh \& Wirojanagud, 1974), which is about $15 \mathrm{~km}$ north of the Siracha site, using loading durations ranging from two minutes to one day per increment; the soil properties were $w_{\mathrm{n}}=130 \%, w_{\mathrm{L}}=120 \%$, $w_{\mathrm{p}}=45 \%$. The normalized shear stress against strain relationships are shown in Fig. 2. Widjaja (1977) employed controlled-strain triaxial tests with strain rates that varied from $0.005 \%$ to $60 \%$ per hour on samples from three depths at Rangsit (Moh et al., 1972), which is $40 \mathrm{~km}$ due north of Bangkok and about $70 \mathrm{~km}$ from the

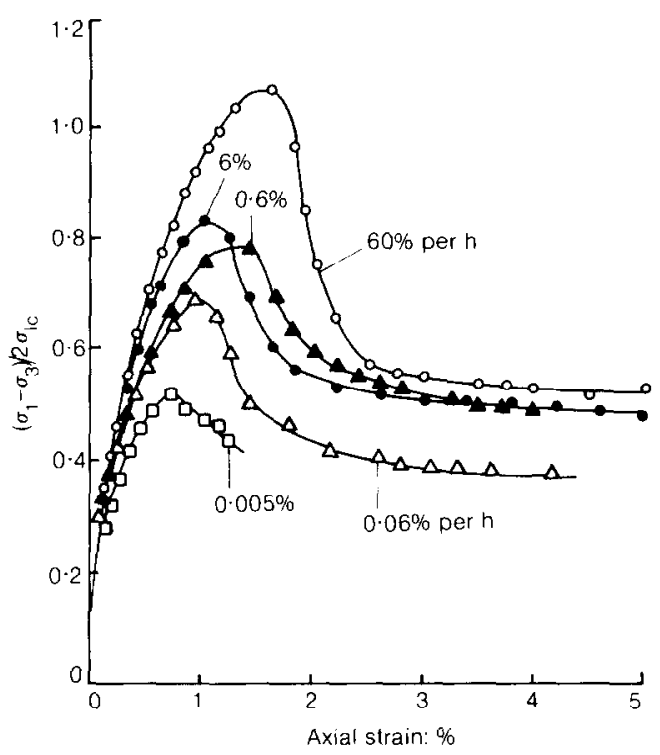

Fig. 3. Stress-strain curves for triaxial compression tests on Rangsit clay from $5.8 \mathrm{~m}$ depth (Widjaja, 1977)

sea. The normalized shear stress against strain curves for the series of tests on the soft clay from a $5.80 \mathrm{~m}$ depth $\left(w_{\mathrm{n}}=84 \%, w_{\mathrm{I}}=90 \%\right.$, $w_{\mathrm{p}}=33 \%$ ) are shown in Fig. 3. The results of the tests on Bangpli and Rangsit clays are summarized in Fig. 4, together with those published by Eide \& Holmberg (1972) for the Siracha clay. It can be concluded that $\rho_{0 \cdot 1}$ lies in the range $10-15 \%$ for the soft Bangkok clay.

In Figs 6 and 7 of the Paper there are very few data points for which $\rho_{0.1}$ exceeds $15 \%$, and most of these are attributable to the results for Bangkok clay published by Bjerrum (1969). If these points are disregarded and the data from Fig. 4 are used instead, the Authors might now feel that they could conclude that the undrained shear strength of any soft clay changes by only $10-15 \%$ for a tenfold change in strain rate.

Armed with a knowledge of the significance of strain-rate effects, the practitioner is faced with the unenviable task of taking account of these in the design of structures on soft clay. The in situ vane test is for good reason extensively used for strength measurements in these materials, and it has been realized for many years that this test overestimates the undrained shear strength. In Sweden, corrections to measured vane strengths have long been made on the basis of the liquid limit of the soft clay (Osterman, 1960a, 1960b; Helenelund, 1977), while Bjerrum $(1972,1973)$ has advocated the use of empirical correction 


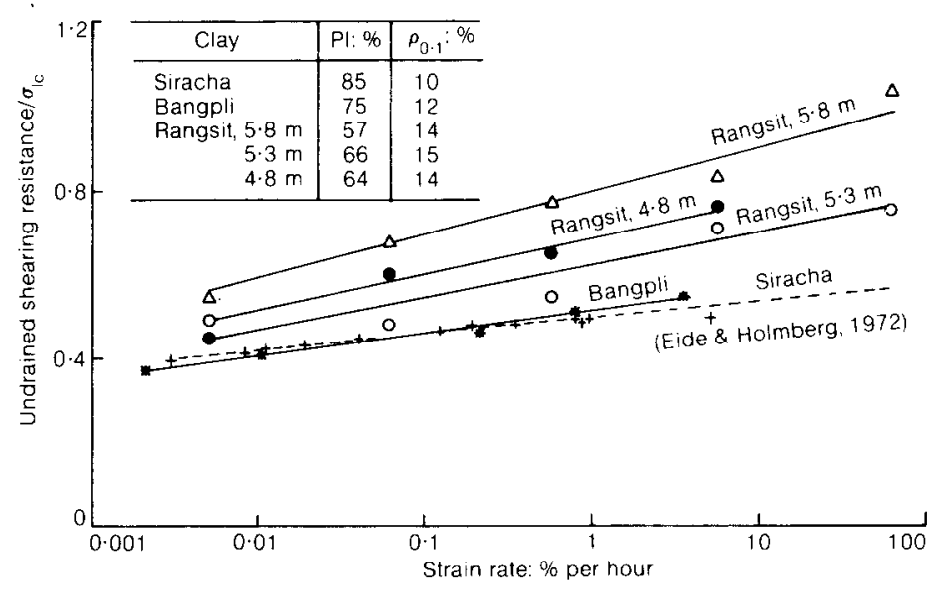

Fig. 4. Change in undrained shearing resistance of Bangkok clay with log (strain rate)

factors related to plasticity to correct theoretical factors of safety calculated from vane data. Bjerrum \& Parry (1971) considered the shear rate effect to be the major source of error inherent in measured vane strengths, and Bjerrum suggested that rate correction factors $\mu_{r}$ should be applied, in addition to correction factors for clay anisotropy and other effects. Bjerrum (1969) had earlier emphasized the overriding significance of shear rate effects with the words

The amount of evidence we have collected is now so complete that the difference between the vane shear strength and the shear strength which can be mobilised under a filling is primarily due to the difference in rate of loading. In order to use the vane shear strength for practical design problems, it is thus necessary to correct it to the appropriate rate of loading.

Extreme difficulty arises, however, with the selection of the 'appropriate rate of loading' under field conditions against which to correct the vane strengths. This will be illustrated by reference to the test embankments loaded rapidly to failure at the Siracha site (Eide \& Holmberg, 1972) and the Bangpli site (Brand et al., 1974) mentioned above.

Eide \& Holmberg (1972) have described three test embankments built simultaneously to failure at the Siracha site. These were built adjacent to each other, largely to examine the stability performance of embankments with berms (Siracha II) and bamboo fascines (Siracha
III) compared with an embankment without either of these (Siracha I). Failure of embankment I occurred at a height of $2.0 \mathrm{~m}, 47$ days after filling began; a crack first formed down the centre of the embankment after it had stood at a height of $2.0 \mathrm{~m}$ for two days, and failure took place 20 minutes later. Embankment III failed during filling at a height of $2.5 \mathrm{~m}$ on the 64th day; vertical cracks occurred longitudinally one hour before failure took place. Embankment II was the last to fail, on the 65 th day, after the embankment had been at a height of $2.5 \mathrm{~m}$ for two days; a longitudinal crack again preceded failure, which occurred during the night at an undetermined rate. The Bangpli test embankment (Moh et al., 1974) failed at a height of $3.4 \mathrm{~m}, 27$ days after filling began. Filling to that height had been completed at $18.00 \mathrm{~h}$ the previous day; a longitudinal crack appeared at about $06.00 \mathrm{~h}$ on the day of failure, and the failure itself took place a few hours later.

The undrained failures of the four test embankments have all been analysed on the basis of field vane tests, which were carried out in a period of only about two minutes. The uncorrected factors of safety at failure are shown in Table 1, together with information pertinent to corrections for shear rate effects. The rate correction factors $\mu_{\mathrm{r}}$ (Bjerrum, 1972, 1973) have been calculated in each case for four definitions of failure time, ranging from the total construction time, at one extreme, to the time during which the process of visible shear failure occurred, at the other extreme. Table 1 shows the difficulties inherent in applying shear rate corrections to factors of safety calculated on the basis of in situ vane tests, since a wide range of 


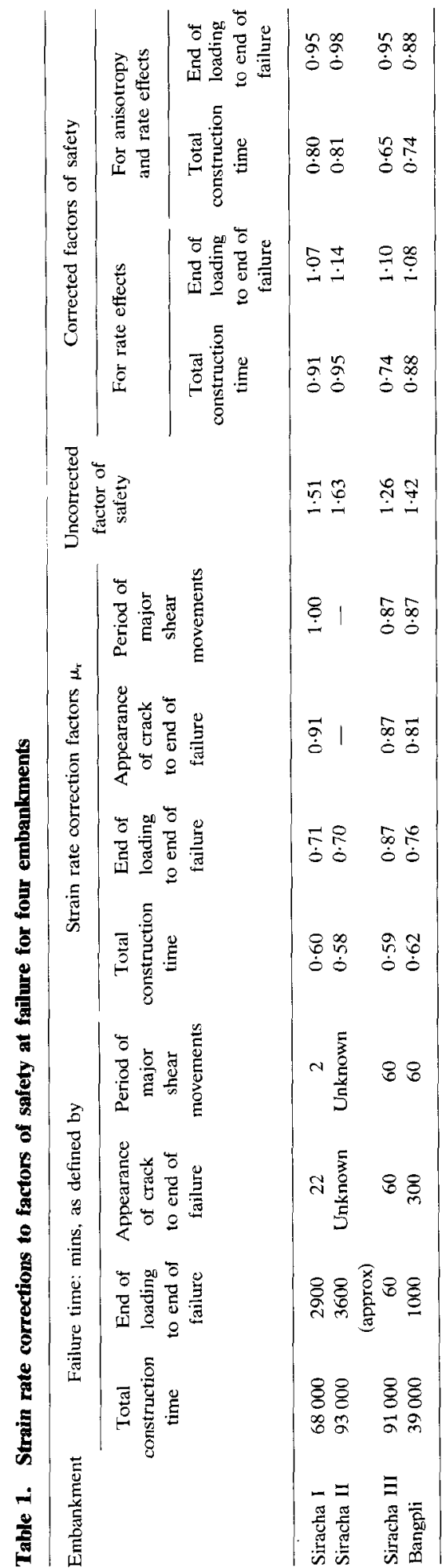

corrected $F$ values can be obtained for any embankment.

It is clear from Table 1 that, if the failure time is taken to be the total construction time, as advocated by Bjerrum $(1969,1972,1973)$, then the factors of safety corrected for rate effects alone are much too low. Corrections for clay anisotropy reduce the $F$ values even further. The results of the stability analyses on the four Bangkok embankments suggest that combined corrections for anisotropy and definition (2) rate effects give factors of safety closest to the correct ones. This conclusion, however, will be of little use to designers of embankments on soft clay, since the time from the end of loading to the end of failure is clearly meaningless at the design stage. It would therefore appear that empirical correction factors of the kind suggested by Bjerrum $(1972,1973)$ must continue to be relied on for design purposes.

\section{REFERENCES}

Bjerrum, L. (1969). Discussion on stability of natural slopes and embankment foundations. Proc. 7th Int. Conf. Soil Mech., Mexico 3, 412-414.

Bjerrum, L. (1972). Embankments on soft ground. Proc. Specialty Conf. Performance of Earth and Earth-Supported Structures, Lafayette, Indiana 2, 1-54. (Reprinted in Norwegian Geotech. Inst. Pub. No. $95,1973$.

Bjerrum, L. (1973). Problems of soil mechanics and construction on soft clays. Proc. 8th Int. Conf. Soil Mech., Moscow 3, 111-159. (Reprinted in Norwegian Geotech. Inst. Pub. No. 100, 1974).

Brand, E. W., Moh, Z. C. \& Wirojanagud, P. (1974). Interpretation of Dutch cone tests in soft Bangkok clay. Proc. Eur. Symp. Penetration Testing, Stockholm 2.2, 51-58.

Eide, O. \& Holmberg, S. (1972). Test fills to failure on the soft Bangkok clay. Proc. Specialty Conf. Performance of Earth and Earth-Supported Structures, Lafayette, Indiana 1, 159-180. (Reprinted in Norwegian Geotech. Inst. Pub. No. 95, 1973.)

Helenelund, K. V. (1977). Methods for reducing undrained shear strength of soft clay. Swedish Geotech. Inst. Rep. No. 3.

Osterman, J. (1960a). Views on the stability of clay slopes. Geol. Fören Förhandl, Stockholm, 82, 346366. (Reprinted in Swedish Geotech. Inst. Reprints and Prelim Reps No. 1, 1960.)

Osterman, J. (1960b). Notes on the shearing resistance of soft clays. Acta Polytech. Scand., Rep. Ci 2(263/1959).

Sunghitakul, A. (1976). Undrained shear strength characteristics of Nong Ngoo Hao clay under controlled stress conditions. MEng thesis, Asian Institute of Technology, Bangkok.

Widjaja, H. (1977). Effect of rate of loading on triaxial shear strength of soft Bangkok clay. MEng thesis, Asian Institute of Technology, Bangkok. 

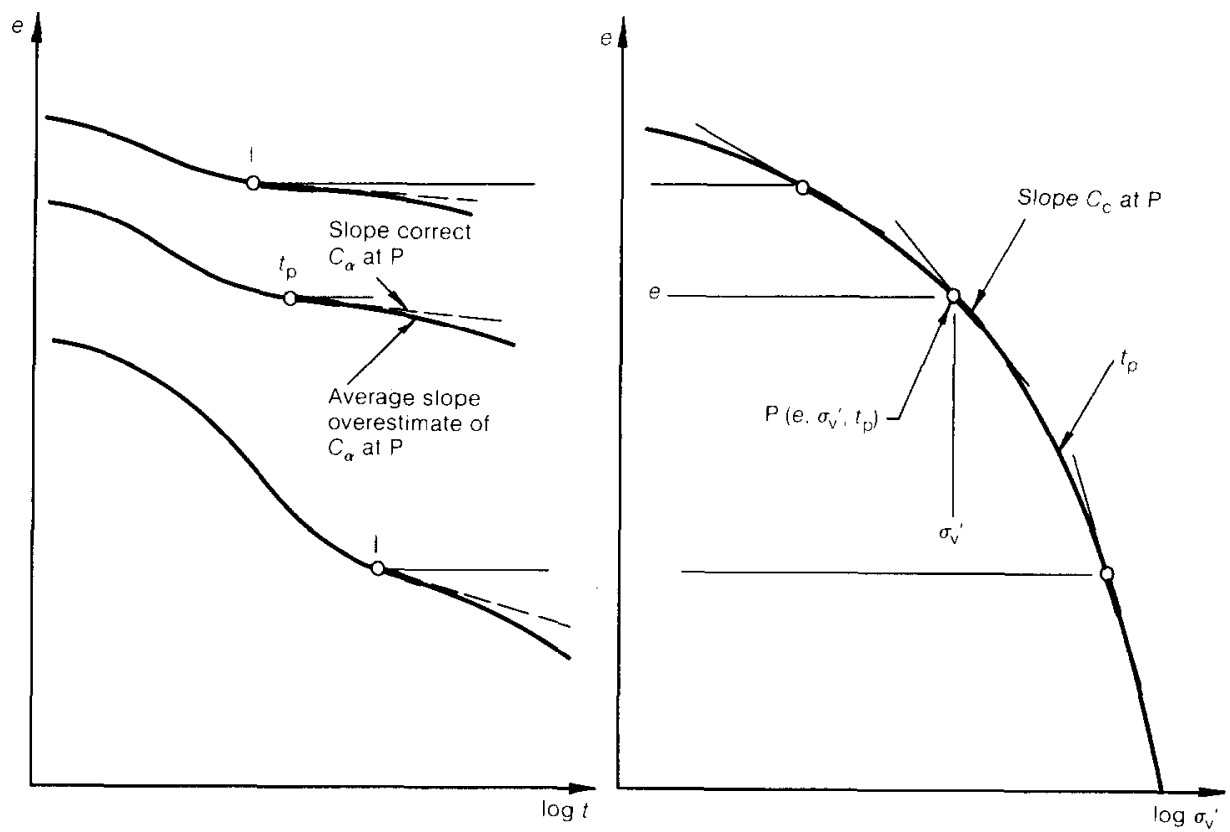

Fig. 5. Evaluation of the corresponding values of $C_{\alpha}$ and $C_{\mathrm{c}}$ at a point $P$

Professor G. Mesri and Mr Y. K. Choi, University of Illinois at Urbana-Champaign

The Authors' data and analyses on consolidation of soft clays generally confirm those previously published by the writers. However, for any single consolidation test the Authors computed higher values of $C_{\alpha} / C_{\mathrm{c}}$ near the preconsolidation pressure. This is in conflict with the writers' observations on a large number of natural soft clays.

The Authors computed values of $C_{\alpha} / C_{\mathrm{c}}$ either by separately evaluating the corresponding values of $C_{\alpha}$ and $C_{c}$, or by using equation (3) of the Paper. With respect to the former approach to evaluating $C_{\alpha} / C_{\mathrm{c}}$ the following observations should be made. For natural soft clays the range of consolidation pressure from $\sigma_{\mathrm{v}}{ }^{\prime} / \sigma_{\mathrm{vc}}{ }^{\prime}=0.75$ to $2 \cdot 0$ represents the destructuration zone at which natural soil structure is destroyed. In this range of consolidation pressure $C_{\mathrm{c}}$ increases with $\sigma_{\mathrm{v}}{ }^{\prime}$ and $C_{\alpha}$ increases with time. Unless extreme care is exercised, there is a tendency to overestimate $C_{\alpha}$ and to underestimate the corresponding value of $C_{c}$. This is illustrated in Fig. 5, which shows three pressure increments and the corresponding end-of-primary $e-\log \sigma_{\mathrm{v}}{ }^{\prime}$ curve. ${ }^{*}$ In this

\footnotetext{
* Although end-of-primary $e-\log \sigma_{\mathrm{v}}{ }^{\prime}$ curve is commonly used to define $C_{c}$, any $e-\log \sigma_{v}^{\prime}$ relationship during secondary compression, with the corresponding values of $C_{\alpha}$, can be used to evaluate $C_{\alpha} / C_{c}$ (Mesri \& Godlewlski, 1977).
}

pressure range $C_{\mathrm{c}}$ and $C_{\alpha}$ increase with effective stress and time, respectively. It is not possible to define $C_{\alpha}$ at point P. Some amount of secondary compression is required in order to define a segment of the secondary compression curve. For this reason the corresponding $C_{\mathrm{c}}$ has to be determined from the slope of the tangent slightly to the right of point $P$. If this is not done and $C_{\alpha}$ is taken as the average slope of the secondary compression curve, this leads simultaneously to an underestimation of $C_{\mathrm{c}}$ and an overestimation of the corresponding $C_{\alpha}$. Thus, apparently high values of $C_{\alpha} / C_{c}$ can be computed in the consolidation pressure range $\sigma_{\mathrm{v}}{ }^{\prime} / \sigma_{\mathrm{vc}}{ }^{\prime}=0 \cdot 75-2 \cdot 0$. In addition to the data which were presented by Mesri \& Godlewski (1977), $C_{\alpha} / C_{c}$ data for seven natural soft clays (Table 2) in Fig. 6 further support the unique value of $C_{\alpha} / C_{c}$ for any one soil. A large part of the scatter in the data is related, in addition to different samples and testing problems, to the inability to define properly the corresponding values of $C_{\alpha}$ and $C_{\mathrm{c}}$ at any point $\left(e, \sigma_{\mathrm{v}}{ }^{\prime}, t\right)$. Also, the unique value of $C_{\mathrm{\alpha}} / C_{\mathrm{c}}$ applies to both onedimensional and isotropic compression tests (Fig. 6(b), (d), (g)).

Now returning to equation (3) of the Paper, it was introduced by Mesri \& Choi (1979) as an approximate expression for computing preconsolidation pressure which results completely from secondary compression. It is an approximation because it ignores void ratio decrease in 
Table 2. Natural soft clays

\begin{tabular}{llcccc}
\hline \multicolumn{1}{c}{ Location } & \multicolumn{1}{c}{ Soil type } & $\begin{array}{c}w: \\
\%\end{array}$ & $\begin{array}{c}w_{\mathrm{L}}: \\
\%\end{array}$ & $\begin{array}{c}w_{\mathrm{p}}: \\
\%\end{array}$ & $\sigma_{\mathrm{p}}{ }^{\prime} / \sigma_{\mathrm{vo}}{ }^{\prime}$ \\
\hline Mexico City & Lacustrine & $311-340$ & 361 & 91 & $1 \cdot 4$ \\
St Alban, Canada & Marine & $48-54$ & 31 & 18 & $1 \cdot 9-2 \cdot 7$ \\
Singapore & Marine & $38-79$ & $54-86$ & $19-32$ & - \\
San Francisco & Coastal marine & $86-97$ & 89 & 37 & $1 \cdot 2$ \\
Olga, Canada & Glacio-lacustrine & $85-94$ & 67 & 29 & $2 \cdot 2-2 \cdot 5$ \\
Broadback, Canada & Glacio-lacustrine & 48 & 36 & 25 & $2 \cdot 6-3 \cdot 2$ \\
Louiseville, Canada & Marine & $64-71$ & 65 & 28 & $2 \cdot 6-2 \cdot 9$ \\
\hline
\end{tabular}

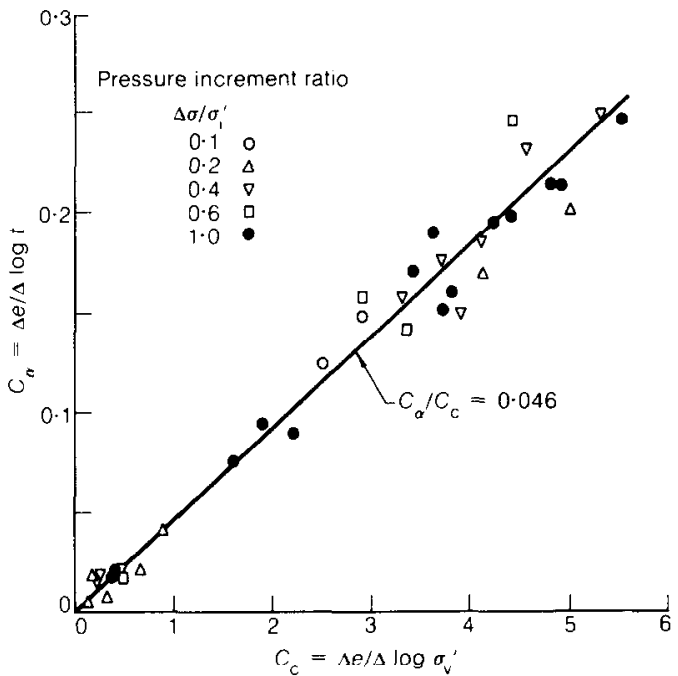

(a)

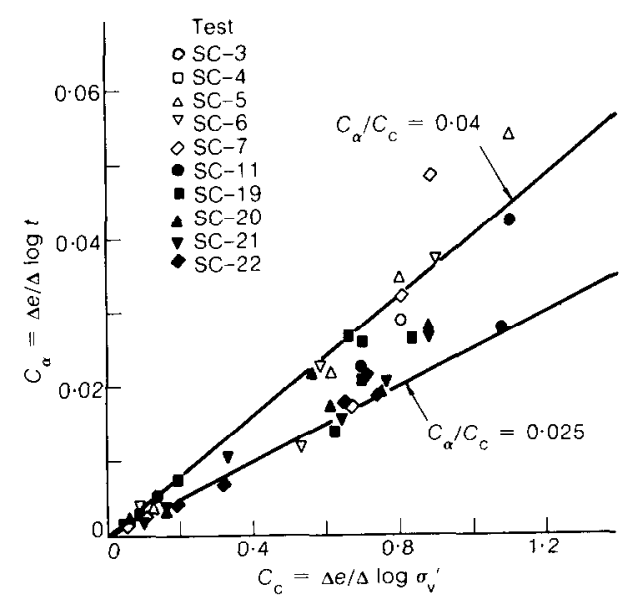

(c)

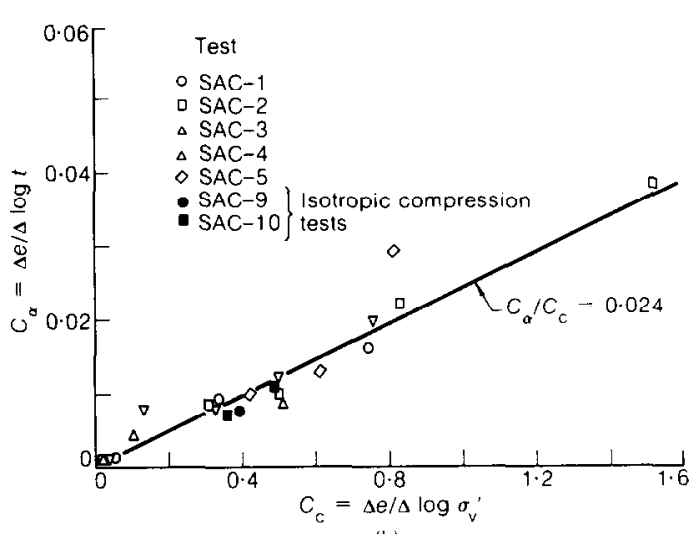

(b)

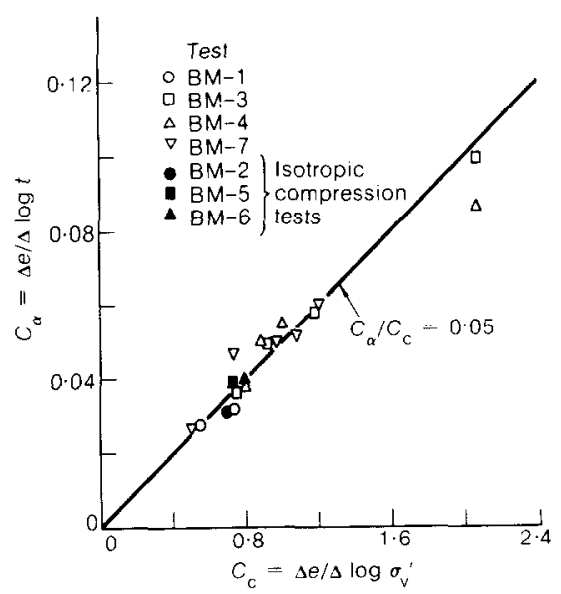

(d)

Fig. 6. $C_{\alpha} / C_{c}$ data for natural soft clays: (a) brown Mexico City clay; (b) St Alban clay; (c) Singapore clay; (d) San Francisco Bay mud. 


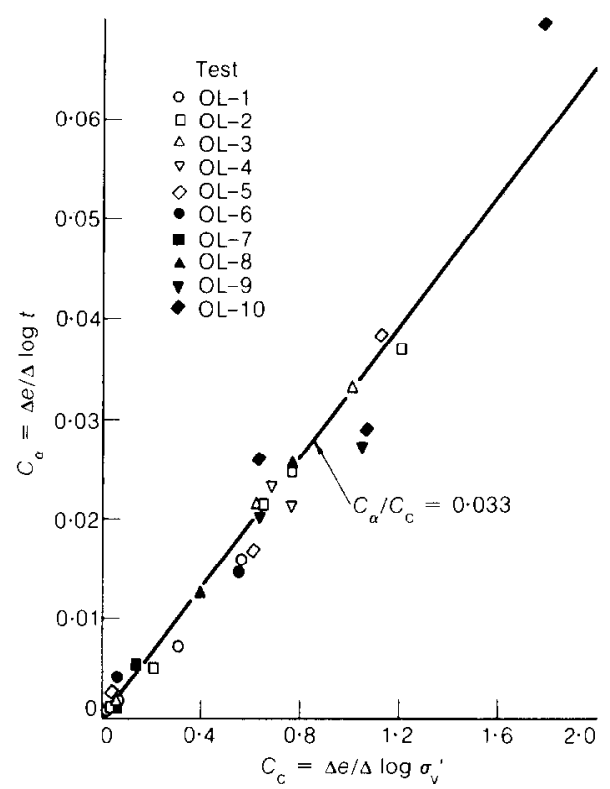

(e)

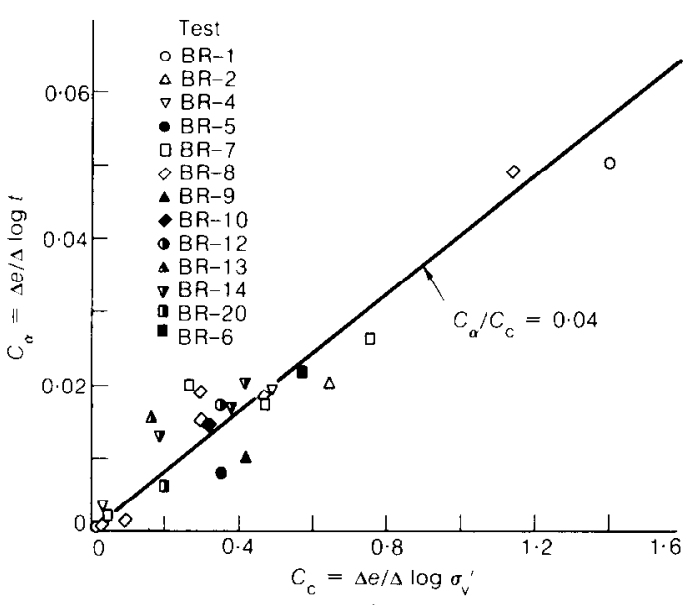

(f)

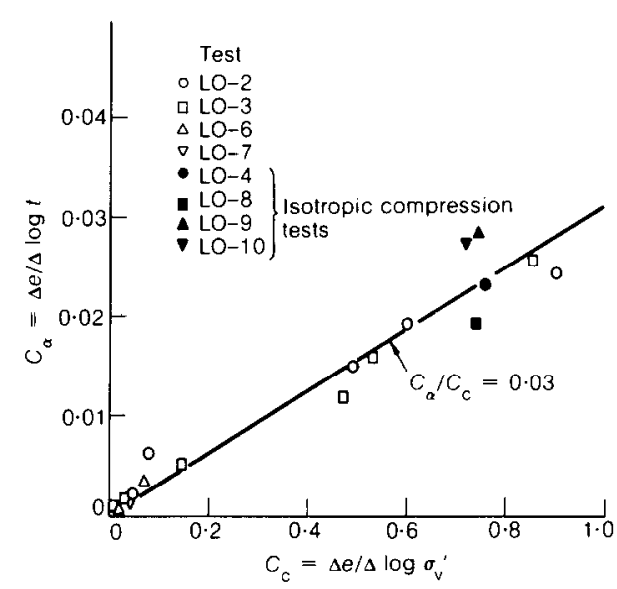

(9)

Fig. 6. -contd: (e) Olga clay; (f) Broadback clay; (g) Louiseville clay

recompression from $\sigma_{\mathrm{vo}}{ }^{\prime}$ to $\sigma_{\mathrm{vc}}{ }^{\prime}$. The exact expression including the recompression with slope $C_{\mathrm{r}}$ is

$$
\frac{\sigma_{\mathrm{vc}}{ }^{\prime}}{\sigma_{\mathrm{vo}}{ }^{\prime}}=\left(\frac{t}{t_{\mathrm{p}}}\right)^{\left(C_{\mathrm{\alpha}^{\prime}} / C_{\mathrm{c}}{ }^{\prime} /\left(1-C_{\mathrm{r}} / C_{\mathrm{c}}\right)\right.}
$$

With $C_{\mathrm{r}} / C_{\mathrm{c}}$ equal to 0 equation (1) simplifies to

$$
\frac{\sigma_{\mathrm{vc}}{ }^{\prime}}{\sigma_{\mathrm{vo}}{ }^{\prime}}=\left(\frac{t}{t_{\mathrm{p}}}\right)^{C_{\mathrm{\alpha}} / C_{\mathrm{c}}}
$$

The simplified expression (2) was given because it is known that clays that have developed a pre- consolidation pressure by secondary compression, cementation or thixotropic bonding mechanisms exhibit low values of $C_{\mathrm{r}} / C_{\mathrm{c}}$ on reloading from $\sigma_{\mathrm{vo}}{ }^{\prime}$ to $\sigma_{\mathrm{vc}}{ }^{\prime}$ (Mesri \& Rokhsar, 1974). Since in natural soft clays $\sigma_{\mathrm{vc}}{ }^{\prime}$ rarely results solely from secondary compression, the simplified equation (2) was considered to be adequate for estimating $\sigma_{\mathrm{vc}}{ }^{\prime} / \sigma_{\mathrm{vo}}{ }^{\prime}$.

However, the approximate expression (2) cannot be used to compute $C_{\alpha} / C_{c}$, as has been done by the Authors, especially in the range $\sigma_{\mathrm{v}}{ }^{\prime} / \sigma_{\mathrm{vc}}{ }^{\prime}=0 \cdot 75-2 \cdot 0$. For natural soft clays near the preconsolidation pressure the incremental 
$C_{\mathrm{r}} / C_{\mathrm{c}}$ is probably both large and highly variable. After the process of destructuration begins it would be difficult to define $C_{\mathrm{r}}$ for small pressure increments in the consolidation pressure range $\sigma_{v}{ }^{\prime} / \sigma_{v c}{ }^{\prime}=0 \cdot 75-2 \cdot 0$. Equation (1) can be rewritten in terms of the Nuthors' notation as

$$
C_{\alpha} / C_{\mathrm{c}}=\left(1-C_{\mathrm{r}} / C_{\mathrm{c}}\right)\left(\log \sigma_{\mathrm{v} 1}{ }^{\prime} / \sigma_{\mathrm{v} 2}{ }^{\prime}\right)
$$

Equation (3) shows that by using different values of $C_{\mathrm{r}} / C_{\mathrm{c}}$ it is possible to obtain a constant value of $C_{\alpha} / C_{c}$ for different values of $\log \sigma_{v 1}{ }^{\prime} / \sigma_{v 2}{ }^{\prime}$ (horizontal distance between the $e-\log \sigma_{\mathrm{v}}{ }^{\prime}$ curves corresponding to $t_{1}$ and $t_{2}$ ). Incidentally, that equation (2) should not be used to compute $C_{\alpha} / C_{\mathrm{c}}$ is also indicated by Fig. 11 of the Paper, because it implies zero value of $C_{\alpha} / C_{\mathrm{c}}$ at a small consolidation pressure. Even equation (3) is not recommended for computing $C_{u} / C_{c}$ because near the preconsolidation pressure it may not be possible to define the incremental $C_{\mathrm{r}} / C_{\mathrm{c}}$.

In order to formulate a more rigorous expression, similar to equation (1), for evaluating the effect of strain rate on the measurement of preconsolidation pressure, an assumption is required with respect to the influence of strain rate on the recompression index. One plausible approach is to assume that the preconsolidation pressure is reached at a critical strain which is independent of the strain rate. Using such an assumption and approximating recompression curves between the present overburden pressure and preconsolidation pressures with constant values of the recompression index $C_{\mathrm{r}}$ gives

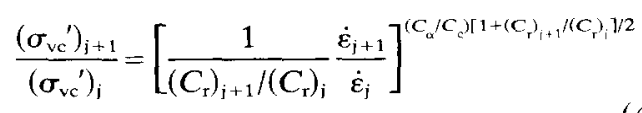

For $\left(C_{\mathrm{r}}\right)_{j+1} /\left(C_{\mathrm{r}}\right)_{j}=1$ equation (4) reduces to

$$
\frac{\left(\sigma_{v c}^{\prime}\right)_{j+1}}{\left(\sigma_{v c}\right)_{j}}=\left(\frac{\dot{\varepsilon}_{j+1}}{\dot{\varepsilon}_{j}}\right)^{C_{d} / c_{c}}
$$

$\dot{\varepsilon}_{j}$ and $\dot{\varepsilon}_{j+1}$ are two successive strain rates such that $\dot{\varepsilon}_{i+1}<\dot{\varepsilon}_{j}$ and $\dot{\varepsilon}_{j} / \dot{\varepsilon}_{j+1} \leqslant 10$. The last restriction is intended to assure that equation (4) is not applied to successive strain rates that are different by more than 10 times. However, a $\sigma_{\mathrm{vc}}{ }^{\prime}$ against $\dot{\varepsilon}$ relationship can be developed by repeated applications of cquation (4). Equation (4) does not apply to the constant rate of strain tests in which significant excess porewater pressure develops in the sample.

It turns out that for $\dot{\varepsilon}_{i+1} / \dot{\varepsilon}_{i}=0 \cdot 1,\left(C_{r}\right)_{j+1} /\left(C_{r}\right)_{i}$ has a limited range of values. An empirical evaluation, based on five sets of constant rate of strain tests, suggests a $\left(C_{\mathrm{r}}\right)_{\mathrm{j}+1} /\left(C_{\mathrm{r}}\right)_{\mathrm{i}}$ range of $1 \cdot 1-$ $1 \cdot 4$, with an average value of about $1 \cdot 2$. For the Belfast clay $\eta_{0-1}=15 \%$ is obtained from equa- tion (4) using $C_{\alpha} / C_{\mathrm{c}}=0.06$ and $\left(C_{\mathrm{r}}\right)_{j+1} /\left(C_{\mathrm{r}}\right)_{\mathrm{i}}=$ 1.2. Using $C_{n} / C_{c}=0.06$ in equation (5) gives $\eta_{0 \cdot 1}=13 \%$. Considering that both computed values of $15 \%$ and $13 \%$ are well within the Authors' experimental data, and that the effect of strain rate on $\left(C_{\mathrm{r}}\right)_{i+1} /\left(C_{\mathrm{r}}\right)_{i}$ is under discussion (Leroueil, Samson \& Bozozuk, 1983), either equation (4) or the simplified equation (5) could be used to examine strain-rate effect on the measurement of preconsolidation pressure.

In summary, the Authors' conclusions with respect to $\eta_{0 \cdot 1}$ remain valid and there is no need for a variable $C_{\alpha} / C_{c}$. The existing consolidation data on many natural soft clays, within the limitations of testing problems and data interpretation, support a practically unique value of $C_{\alpha} / C_{c}$ for any one soil.

\section{REFERENCES}

Leroueil, S., Samson, L. \& Bozozuk, M. (1983). Laboratory and field determination of preconsolidation pressures at Gloucester. Can. Geotech. J. 20, No. 3, 477-490.

Mesri, G. \& Choi, Y. K. (1979). Discussion: Strain rate behavior of Saint-Jean-Vianney clay. Can. Geotech. J. 16, No. 4, 831-834.

Mesri, G. \& Godlewski, P. M. (1977). Time- and stress-compressibility interrelationship. J. Geoterh. Engng Div. Am. Soc. Civ. Engrs 103, GT 5, 417430 .

Mesri, G. \& Rokhsar, A. (1974). Theory of consolidation for clays. J. Geotech. Engng Div. Am. Soc. Civ. Engrs 100, GT 8, 889-904.

\section{Authors' reply}

The objective of the Paper was simply to quantify the influence of strain rate on common behavioural properties of clays. All natural and man-made materials exhibit time-rate or strainrate effects. In view of the complex, loosely bonded, particulate nature of natural clays, they could be expected to be particularly susceptible to time effects. Also, as the effects are inherent to the particle structure, they should be evident in virtually all aspects of clay behaviour.

It was not our intent to identify 'correct' values of these properties for use in analysis and design. That is a separate, and perhaps contentious issue that requires further attention. For example, we presented data on the effects of strain rate on preconsolidation pressures $\sigma_{v c}{ }^{\prime}$ as commonly measured. However, it is known that $\sigma_{\mathrm{vc}}{ }^{\prime}$ is uniquely defined from primary consolidation strains only. Inclusion of arbitrary amounts of secondary consolidation in slow tests, or incomplete consolidation in fast tests, precludes definitions of $\sigma_{\mathrm{vc}}$ ' in this way. Similarly, it was not our intention to define the 'correct' undrained shear strength for field analysis, but 
rather to indicate that differences in strain rate affect the measured values. However, since the writers' interest focused largely on the applicability of the data to field situations, we have formulated our reply in these terms.

\section{Undrained shear}

Dr Schmertmann draws attention to the possibility that significant drainage can occur in field situations corresponding to slow strain rates. $\mathrm{He}$ therefore suggests that the applicability of our data is limited. We agree that shearing resistance may increase at slow rates of strain if drainage is significant. The explanation that strength increases are related to particle reorientation or dispersion is reasonable. However, we do not accept that complete or even significant drainage of foundation clays is as common as Dr Schmertmann infers, and that our use of undrained tests to examine the effects of strain rate on strength constitutes an important limitation. Folkes (1980) analysed fills on soft clay involving normal rates of loading, fill/subsoil geometry and boundary drainage conditions. $\mathrm{He}$ concluded that the response of soft foundation clay during and immediately after construction is usually undrained. Significant drainage is the exception rather than the rule. For some time following construction, the effective stresses lie inside or on the original yield envelope. Consideration of undrained strength is therefore necessary, and the effect of strain rate on measured undrained strength is a significant issue.

Dr Brand raises an interesting practical question with respect to strain-rate corrections-how is the field strain rate to be established? His analysis of the Bangkok embankments suggests that correction of undrained strength for strainrate effect is greatly influenced by the definition of field strain rate, and is therefore arbitrary. Other 'corrections' are reportedly required to account for anisotropy, progressive failure and mobilized crust/fill strengths. Given the uncertainty indicated by this profusion of correction factors, it appears that the current understanding of clay behaviour based on total stress/limit equilibrium approaches is inadequate. Some of the confusion is perhaps caused by backanalyses of failures which assume incorrect failure mechanisms (for example, circular instead of translational failure), or which do not properly account for weak layers in the foundation soils (Leonards, 1982).

Dr Brand also presents useful additional $\rho_{0.1}$ data for Bangkok clay which may reduce the upper limit of strain-rate effect. It is interesting that these additional data also show no tendency

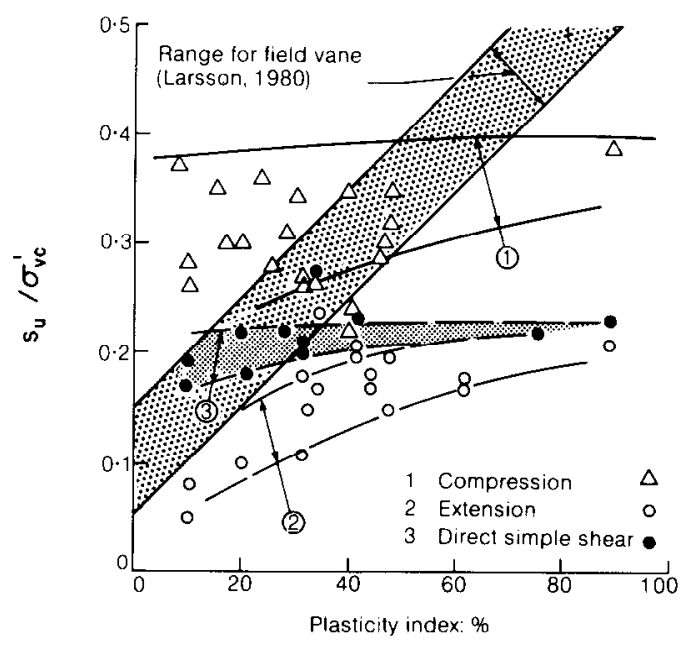

Fig. 7. Values of normalized undrained strengths from different test types

for $\mu_{0-1}$ to decrease or tend to zero at low rates of strain.

At the end of his discussion, Dr Brand suggests that an empirical correction factor such as that proposed by Bjerrum is required. We have some difficulty with this. As Dr Brand points out, the main basis of Bjerrum's correction factor is that undrained strength is strain-rate dependent. Presumably since $\mu_{R}$ increases with plasticity index, the magnitude of the strain-rate effect parameter $\rho_{0.1}$ should also increase with plasticity. However, the data in Fig. 7 of the Paper clearly demonstrate that this is not so. Figure 7 of the discussion indicates that, for whatever reason, vane strengths increase significantly with plasticity, although this trend is not observed in laboratory strength measurements. Despite important continuing studies of the vane test, we agree with Dr Brand that at this time, embankment design must contain an empirical component. However, the reasons are probably different from those proposed by Bjerrum. It is our impression that more intensive hack-analysis of failures is required as suggested by Leonards (1982), rather than adoption of empirical correction factors that do not address the fundamentals of the problem.

\section{Consolidation behaviour}

From consideration of particle redistribution and dispersion Dr Schmertmann confirms that 'stiffening' of clay during drained loading is not reversible. In the same way that preconsolidation pressures are best defined from primary consolidation strains only, so quasi-preconsolidation pressures developed by aging 
should in principle be independent of arbitrary amounts of delayed or secondary consolidation. On this basis they can be considered permanent and independent of strain rate. However, we have no data which examine this question directly.

Dr Mesri and Dr Choi dispute our contention and that of other researchers such as Leonards \& Girault (1961) that $C_{\alpha} / C_{\mathrm{c}}$ is higher in the pressure range close to $\sigma_{\mathrm{vc}}$ ' than at other pressures. We accept their suggestion that estimates of $C_{\alpha}$ and $C_{c}$ could be erroneous if determined separately in the preconsolidation stress range. We also accept that the approximate expression we used to compute $C_{\alpha} / C_{\mathrm{c}}$ is not fully correct because $C_{\mathrm{r}} / C_{\mathrm{c}}$ is not taken into account. The exact solution presented by Mesri and Choi (their equations (1) and (3)) can be used to demonstrate that $C_{\alpha} / C_{\mathrm{c}}$ can be constant for all stresses if $C_{\mathrm{r}} / C_{\mathrm{c}}$ is varied. However, as they indicate, $C_{\mathrm{r}} / C_{\mathrm{c}}$ cannot be readily measured in the preconsolidation pressure stress range. These expressions therefore provide the possibility, but not the proof, that $C_{\alpha} / C_{\mathrm{c}}$ is constant.

Mesri and Choi note that Fig. 11 implies $C_{\alpha} / C_{\mathrm{c}}$ is zero in the low stress range. The figure is diagrammatic and was intended for illustration purposes only. $C_{c},\left(C_{r}\right)$ and especially $C_{\alpha}$ are small at low stresses, and calculated values of $C_{\alpha} / C_{c}$ could therefore be significantly in error. Mesri and Choi propose a more rigorous expression (equation (4)) which indicates that $\boldsymbol{\eta}_{0.1}$ can be computed without assuming variation of $C_{\alpha} / C_{\mathrm{c}}$. Because of the assumption of constant critical strain at $\sigma_{\mathrm{vc}}$, and empirical evaluation of $C_{\mathrm{r}(j+1)} / C_{\mathrm{r}(j)}$, the equation does not itself prove that $C_{\alpha} / C_{\mathrm{c}}$ is constant. Thus it appcars that whether $C_{\alpha} / C_{\mathrm{c}}$ is constant for a given soil, or increases in magnitude at $\alpha_{\mathrm{vc}}$ ', remains open to question.

These are complex questions. Further work is clearly required, particularly regarding the inclusion of consideration of strain-rate effects in design problems.

\section{REFERENCES}

Folkes, D. J. (1980). Stress path behaviour below embankments on soft clay. MSc thesis, University of Toronto.

Leonards, G. A. (1982). Investigation of failures. J. Geotech. Engng Div. Am. Soc. Civ. Engrs, 108, GT $2,185-246$.

Leonards, G. A. and Girault, P. (1961). A study of the one-dimensional consolidation test. Proc. 5th Int. Conf. Soil Mech., Paris 1, 213. 